\title{
A case of hysteria: anti-N-methyl-D-aspartate receptor encephalitis resulting from a mature ovarian teratoma
}

\author{
Colette M. Gnade, ${ }^{1}$ Heather R. Williams, ${ }^{2}$ Colleen K. Stockdale ${ }^{2}$
}

\begin{abstract}
Keywords: Anti-N-methyl-D-aspartate receptor encephalitis, mature teratoma of the ovary, dermoid, autoimmune encephalitis, young women
\end{abstract}

\begin{abstract}
Anti-N-methyl-D-aspartate receptor encephalitis in young healthy women while rare may be the result of an ovarian teratoma that produces antiNMDA receptor antibodies. Symptoms from this encephalitis can be severe enough to result in hypoventilation, autonomic instability, and coma. Although treatable with tumor removal via oophorectomy and immunosuppression, median time to diagnosis is 8 weeks, which may lead to the onset of severe symptoms.

The case presented highlights the severity of symptoms including rhabdomyolysis and respiratory distress in a female who had a previous history of functional somatic syndromes, which possibly resulted in a delayed diagnosis. This case demonstrates the importance of a thorough evaluation for causes of new onset neurological symptoms when the patient's clinical status continues to deteriorate. This includes an evaluation for anti-N-methyl-Daspartate receptor encephalitis. Following salpingo-oophorectomy,

IVIG/methylprednisolone, and rituximab/cyclophosphamide treatment, this
\end{abstract}

patient demonstrated improvement although she continues to require rehabilitation therapy, maintenance Keppra and low-dose Prednisone.

\footnotetext{
${ }^{1}$ University of lowa Carver College of Medicine, lowa City, lowa

${ }^{2}$ University of lowa Hospitals and Clinics, Department of Obstetrics and Gynecology, lowa City, lowa
}

\section{Introduction}

Anti-N-methyl-D-aspartate receptor encephalitis is a paraneoplastic syndrome resulting in Ig-G antibodies against the NR1 or NR2 subunits. $^{1}$ Although rare, it is the second most common cause of immune-mediated encephalitis secondary to antibodies to the N-methyl D-aspartate receptor and may be the cause of encephalitis in up to $4 \%$ of patients. $^{2}$ The majority of patients initially present with a prodromal syndrome, which can include

Please cite this paper as: Gnade CM, Williams HR, Stockdale. A case of hysteria: anti-N-methyl-D-aspartate receptor encephalitis resulting from a mature ovarian teratoma. Proc Obstet Gynecol. 2016;6(1): Article 5 [ 6 p.]. Available from: http://ir.uiowa.edu/pog/ Free full text article.

Corresponding author: Heather R. Williams, MD, University of lowa Hospitals and Clinics, Department of Obstetrics and Gynecology, 200 Hawkins Drive, lowa City, IA 52242. Email: heather-williams@uiowa.edu

Financial Disclosure: The authors report no conflict of interest.

Received: 12 February 2016; accepted 21 March 2016.

Copyright: (c) 2016 Gnade et al. This is an open-access article distributed under the terms of the Creative Commons Attribution License, which permits unrestricted use, distribution, and reproduction in any medium, provided the original author and source are credited. 
headache, nausea/vomiting, fatigue and upper-respiratory tract symptoms. Less than two weeks later, neuropsychiatric symptoms develop. These can be variable and include behavior and cognition problems, memory deficits, seizures, movement disorders and autonomic symptoms. Up to $77 \%$ of these patients are initially seen by psychiatrists and misdiagnosed with new-onset schizophrenia or bipolar disorder. ${ }^{3}$ If untreated, the disease can lead to lethal hypoventilation, autonomic instability, and catatonia. ${ }^{4}$ Given approximately $60 \%$ of cases in women are caused by an ovarian teratoma, it is important to rule out an ovarian mass when anti-NMDA encephalitis is in the differential diagnoses. ${ }^{1,5}$

Despite detection in 1997 and being formally defined in 2007 , it is typically not considered in the initial differential diagnosis leading to treatment delays up to 8 weeks. ${ }^{4}$ We present a case in which the patient developed rhabdomyolysis and acute respiratory failure before anti$\mathrm{N}$-methyl D-aspartate receptor encephalitis from a $7 \mathrm{~cm}$ left ovarian teratoma was diagnosed and removed.

\section{Case Report}

A 31 year old Gravida 2 Para 2 with a history of Ehlers-Danlos, fibromyalgia and chronic back pain initially presented to an outside hospital for a worsening headache, left lower extremity weakness, falling, and palpitations. She developed a headache 3 days before presentation. She had experienced episodes of weakness in her arms and legs resulting in three falls. Upon evaluation in the emergency department, she developed aphasia and had a tonic-clonic seizure. Subsequent evaluation including MRI revealed no abnormality. A transfer to our institution was requested and granted for further evaluation by Neurology. An EEG was performed during her spells and was unremarkable. She was discharged on hospital day 3 with the diagnosis of new onset generalized tonic-clonic seizures and a urinary tract infection with follow up planned in 3 months.

Two weeks later, she re-presented to the outside hospital with persistent weakness and continued spells. After a two week admission at the outside hospital, she was transferred back to our institution and admitted to Neurology. Pseudoseizures were initially suspected, initiating transfer to Psychiatry for further evaluation. Overnight, she developed jerking episodes, tachycardia to the $170 \mathrm{bpm}$ 's, tachypnea with respiratory rate in 40's and febrile to $40.6^{\circ} \mathrm{C}$. Further labs revealed rhabdomyolysis with a creatine kinase of $40,000 \mathrm{U} / \mathrm{L}$ and acute kidney injury with a creatinine of $2.5 \mathrm{mg} / \mathrm{dL}$. She continued to deteriorate and was transferred to the medical intensive care unit due to acute respiratory decompensation necessitating intubation. Subsequently the patient was evaluated for autoimmune encephalitis, including cerebral spinal fluid analysis for paraneoplastic syndromes, West Nile Virus, HSV 1/2, and the anti-NMDA receptor antibody. A gynecologic ultrasound was also requested to evaluate for a teratoma. Transabdominal ultrasound revealed a $6.8 \times 3.9 \times 5.7 \mathrm{~cm}$ solid mass with cystic components, calcifications and striations consistent with a mature teratoma (Figure 1). 


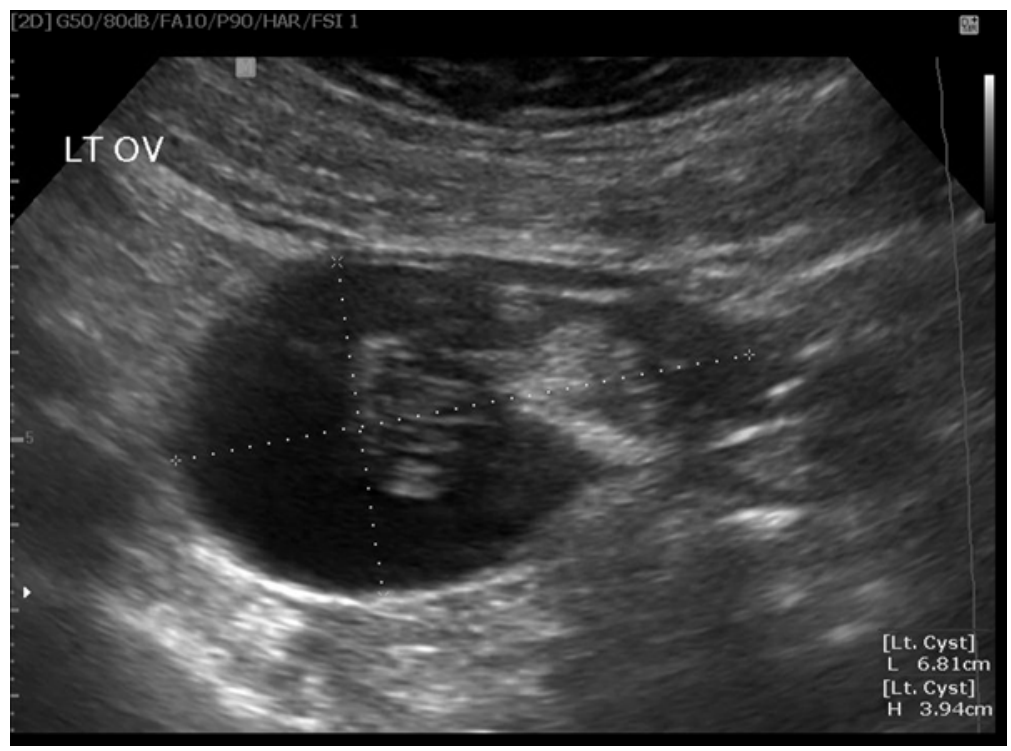

Figure 1: Transabdominal Ultrasound imaging demonstrating striations within the cystic component that most likely represent hair.

Upon discovery of the pelvic mass, Gynecology was consulted for surgical intervention as the patient was rapidly deteriorating and the primary team was concerned the likely teratoma was the source of antibodies causing the patient's encephalitis. The patient was unable to give consent given intubated and sedated status; however, consent was obtained from her mother who noted the patient had completed child bearing as evidenced by her history of tubal ligation. The patient was taken to the operating room and a laparoscopic left salpingo-oophorectomy was performed. Figure 2 demonstrates laparoscopic findings. Upon removal, sebum and hair were present within the mass, making the likely diagnosis of teratoma. Pathology later confirmed a mature teratoma containing hair bearing skin and an immature tooth. Later,
NMDA-receptor antibodies in the CSF and serum returned positive titers of $1: 128$ and $1: 40$ respectively.

The patient was started on IVIG therapy for 4 days and IV methylprednisolone for 5 days. She did relapse 10 days later and was then started on rituximab, which was given weekly for a total of four doses. One week later, cyclophosphamide was initiated as well with improvement noted after one day. She was extubated and continued to regain her baseline functional status. She was discharged to a rehabilitation facility on clonazepam and levetiracetam for myoclonus and prednisone for immunosuppression. After five months she continues to have some difficulty with ambulatory balancing, but her myoclonus has resolved and her cognitive function has fully returned. 


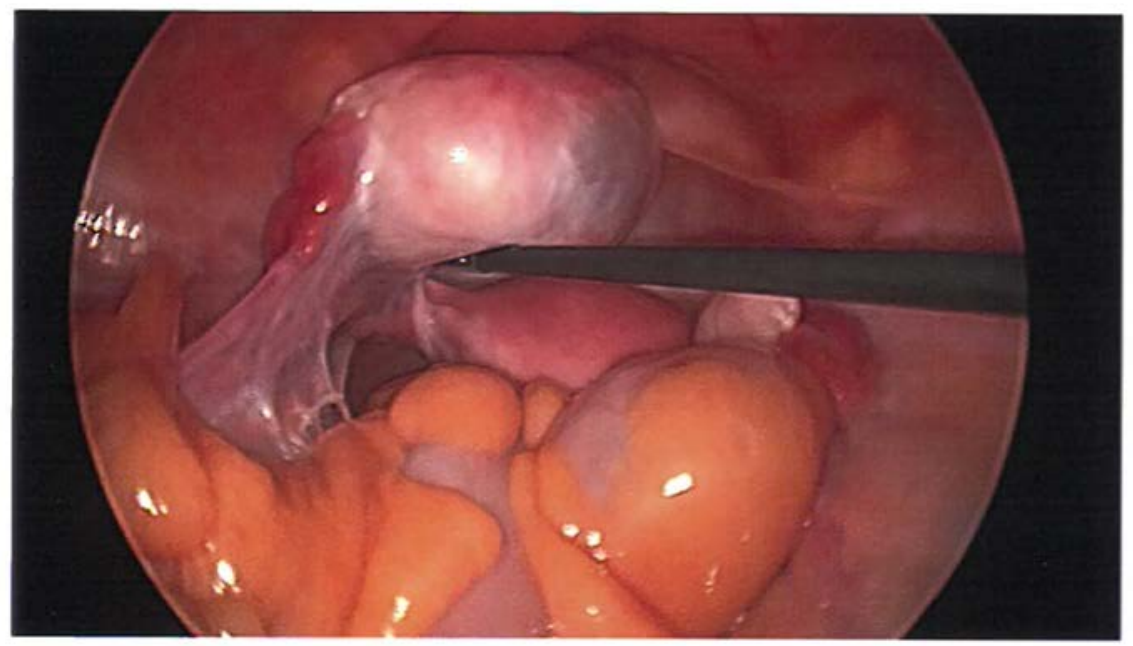

Figure 2: Intraoperative view of the $3.8 \times 6.2 \times 5.5 \mathrm{~cm}$ left ovarian teratoma.

\section{Discussion}

Anti-N-methyl-D-aspartate receptor encephalitis typically presents in young, healthy women under 45 years with prodromal symptoms reflecting the common cold that progress to excitotoxic symptoms such as seizures, movement disorders, and autonomic instability. ${ }^{1,3}$ Up to $60 \%$ of the time, these patients will have an underlying ovarian teratoma that, when removed in combination with immunotherapy can result in recovery and resolution of symptoms ${ }^{4}$ as demonstrated in the case presented. Neuronal tissue in the teratoma is usually the source of the antibody production; however, other tissue such as squamous tissue has been shown to stain positive for the antibody. ${ }^{6}$ Currently the tissue is only tested for experimental purposes given the rarity of this condition and cost of the immunochemical stains. While anti-Nmethyl-D aspartate receptor encephalitis is uncommon, mature teratomas are in fact common. It is worth noting that mature teratomas have an incidence of $20-25 \%$ and the vast majority of the time they will have an indolent course. ${ }^{5}$

Unfortunately, early diagnosis is often missed in patients with underlying functional somatic syndromes as with our patient. Younger female patients presenting with new onset seizure-like activity combined with mood lability should be tested for anti-N-methyl-Daspartate receptor encephalitis if EEG is non-diagnostic. It still remains a challenge when symptoms mainly consist of mood disturbances, agitation, or other seizure like activity as this can result in a psychiatric consult instead of a medicine or neurology consult. It is important in these instances to also evaluate for an organic pathology before solely accepting the functional diagnoses to avoid a delay in treatment. The longer diagnosis is delayed, the 
more likely the patient will develop more severe excitotoxic symptoms. ${ }^{4}$ These can include hypoventilation, coma, or status epilepticus. ${ }^{3}$

Full recovery rates are increased with early tumor removal versus late or no removal (72\% versus $36 \%$ ) as well as a decreased rate of fatality. ${ }^{4,5}$ Immediate removal of the teratoma, along with immunotherapy is recommended. First line therapy is typically IV methylprednisolone and IVIG or plasmapheresis. ${ }^{3}$ If continued autonomic instability or neuropsychiatric symptoms are present, the patient should be given rituximab and cyclophosphamide. ${ }^{3}$ Patients typically recover, but this is dependent on the timing of symptom presentation to treatment.

In our patient, delayed diagnosis resulted in development of rhabdomyolysis from status epilepticus and acute respiratory failure due to prolonged hypoxemia. This case highlights the importance of keeping anti-N-methyl-D-aspartate receptor encephalitis in the differential when the patient is presenting with new onset seizure like activity in combination with neurological and mood disturbances as missing the diagnosis can significantly alter the patient's chance of intact survival.

\section{References}

1. Dalmau J, Lancaster E, MartinezHernandez E, Rosenfeld MR, BaliceGordon R. Clinical experience and laboratory investigations in patients with anti-NMDAR encephalitis. Lancet Neurol. 2011 Jan;10(1):63-74. http://dx.doi.org/10.1016/S14744422(10)70253-2 PubMed PMID:
2. Granerod J, Ambrose HE, Davies NW, Clewley JP, Walsh AL, Morgan D, Cunningham $\mathrm{R}$, Zuckerman $\mathrm{M}$, Mutton $\mathrm{KJ}$, Solomon T, Ward KN, Lunn MP, Irani SR, Vincent A, Brown DW, Crowcroft NS; UK Health Protection Agency (HPA) Aetiology of Encephalitis Study Group. Causes of encephalitis and differences in their clinical presentations in England: a multicentre, population-based prospective study. Lancet Infect Dis. 2010 Dec;10(12):83544. http://dx.doi.org/10.1016/S14733099(10)70222-X Epub 2010 Oct 15. Erratum in: Lancet Infect Dis. 2011 Feb;11(2):79. PubMed PMID: 20952256.

3. Mann AP, Grebenciucova E, Lukas RV. Anti-N-methyl-D-aspartate-receptor encephalitis: diagnosis, optimal management, and challenges. Ther Clin Risk Manag. 2014 Jul 1;10:517-25. http://dx.doi.org/10.2147/TCRM.S61967 eCollection 2014. PubMed PMID: 25061311.

4. Dalmau J, Gleichman AJ, Hughes EG, Rossi JE, Peng X, Lai M, Dessain SK, Rosenfeld MR, Balice-Gordon R, Lynch DR. Anti-NMDA-receptor encephalitis: case series and analysis of the effects of antibodies. Lancet Neurol. 2008 Dec;7(12):1091-8.

http://dx.doi.org/10.1016/S14744422(08)70224-2 Epub 2008 Oct 11. PubMed PMID: 18851928.

5. Kort DH, Vallerie AM, DeMarco EF, Lobo RA. Paraneoplastic anti-N-methyl$\mathrm{d}$-aspartate-receptor encephalitis from mature cystic teratoma. Obstet Gynecol. 2009 Aug;114(2 Pt 1):373-6. http://dx.doi.org/10.1097/AOG.0b013e3 181af6bb6 PubMed PMID: 19623000. 
6. Clark RM, Lynch MP, Kolp R, Zukerberg LR, Growdon WB, Rueda BR. The Nmethyl-D-aspartate receptor, a precursor to N-methyl-D-aspartate receptor encephalitis, is found in the squamous tissue of ovarian teratomas. Int J Gynecol Pathol. 2014 Nov;33(6):598-606.

http://dx.doi.org/10.1097/PGP.00000000 00000104 PubMed PMID: 25272299. 